\title{
The Effects of Dora the Explorer on Preschool Children's Spatial Concept Acquisition and Spatial Ability
}

\author{
Duriye Esra Angın, (Assist. Prof. Dr.) \\ Adnan Menderes University/Faculty of Education, Turkey
}

doi: 10.19044/esj.2017.v13n1p39 $\quad$ URL:http://dx.doi.org/10.19044/esj.2017.v13n1p39

\begin{abstract}
The purpose of this research is to investigate the effects of Dora the Explorer cartoon on the spatial concept acquisitions and spatial abilities of the preschool children. The study was carried out with 80, 60-71 month old children attending preschools. Post-test only control group model is used in the research in order to identify the existing phenomena in a controlled manner. "The Bracken Basic Concept Scale, Third Edition: Receptive (BBCSIII:R) Form Direction/Position Subscale" and two different "Spatial Ability Games" were used to assess children's spatial concept acquisitions and spatial abilities. Independent sample t-test was used in order to compare the average of post-test scores of the children in the experimental and control groups. According to the findings, it is found that there is meaningful difference between scores of post-tests of direction/position subscale and spatial ability games score. Comparing the scores of post-test of direction/position subscale and spatial ability games of experimental and control groups, it was found that there was a meaningful differentiation in favor of experimental group.
\end{abstract}

Keywords: Preschool children, spatial concept acquisition, spatial thinking, map skills, cartoon

\section{Introduction}

Teaching geography is an intellectual process that is supported by one or many "pictures" of the space. In order to create an approach to describe the space, some tools are needed for recording and depicting such as the Maps (Koutsopoulos \& Pigaki, 2007). Maps represent visual information related to the environment. They are means of iconization of the World choice (Goria \& Papadopoulou, 2008). Maps are the major tools of geography; therefore, it is expected that they might be the main trust of the research in primary geography education would be related to children's use and understanding of them (Wiegand, 1999). 
For any age group of students, maps are an integral part of the geography training, and there are already several studies in the literature, which make specific suggestions about teaching maps to young children. Using a map effectively is a complex task that involves a number of competencies (Uttal \& Wellman, 1989). The ability of using a map is an important spatial skill for both daily lives, where maps commonly presented as aids to navigation in novel spaces, and courses, in which spatial information frequently presented in two dimensional forms (Blades \& Spencer, 1986; Bremner \& Andreasen, 1998).

Spatial concepts are some kind of implicit knowledge; their development is difficult to investigate (Peter, Glück, \& Beiglböck, 2010). Spatial information concerns shapes, locations, paths, relations among entities and relations between entities and frames of reference (Newcombe \& Shipley, 2012). Spatial skills involve the ability to think and reason through comparison, manipulation, and transformation of the mental pictures (Casey et al., 2008). Understanding the maps offers one possibility of investigating children's understanding of spatial relations; and comprises three components that can be assessed in an independent way for understanding symbolic representations, use of spatial relations and mental rotation (Peter, Glück, \& Beiglböck, 2010).

Spatial thinking has a vital role in our daily lives where we are interacting with environment, other people, natural objects, human-made objects, and human-made structures that exist somewhere in the space. These things must be understood in terms of locations, distances, directions, shapes and patterns such as navigating in a new city or finding a car in a parking lot when approaching from a different direction, recognizing and manipulating objects and academic tasks (National Research Council of the National Academy, 2006; Tzuriel \& Egozi, 2010; Levine, Huttenlocher, Taylor, \& Langrock, 1999). When we consider rearranging the furniture in a room, following assembly directions for toys, assembling a bookcase using a diagram, or when we relate a map to the road ahead of us, we also use spatial thinking to describe non spatial situations, such as talking about being close to a goal or describing someone as an insider (Newcombe, 2010; Ehrlich, Levine, \& Goldin-Meadow, 2006). As long as children acquire new and more sophisticated ways of mentally representing and using spatial information, their understanding of maps improves. Likewise, children's developing conception of maps affects how they understand and conceive of spatial information (Uttal, 2000). Children learn positional vocabulary and use it with their bodies in order to develop spatial awareness. This is how children begin to develop an understanding of direction, distance, and location (Poole, Miller, \& Church, 2006). 
Piaget and Inhelder (1967) suggest that a child's understanding of spatial abilities develops in a three stages including: preoperational, concrete operational and formal operational continuum (as cited in Dyanne, 1988). According to Mohler (2008), conducted studies in this area, childhood experiences as well as access to toys and other experiences are the basis for the development of spatial ability. When childhood experiences are thought, cartoons also come to mind. Cartoons represent a form of art that has been promoted into an important visual language, which influences the human sentiments and transmits messages by using some symbols and pictures. They constitute a combination of humor, exaggeration, and symbols, while presenting a subject with the simplest lines possible (Dalacosta, KamariotakiPaparrigopoulou, Palyvos, \& Spyrellis, 2009).

Every weekday, millions of preschool children watch the Dora the Explorer (DtE) television program, in which a seven-year-old Latina cartoon character navigates the environment to reach some destinations and solves problems. On every program, children have to call forth a map and at many steps during the program, the children view one or more maps as Dora teaches counting, colors, shapes, language, and also map-reading during the show (Carter, 2008).

In each episode, using a map to point out the stops on the way, Dora and the viewer must solve problems and overcome obstacles along the way to achieve their goals (Nickelodeon, 2013a). DtE came to television in 2000 on Nickelodeon Junior, which is a commercial channel on cable and satellite. Many of the episodes of DtE are available on video tapes and DVDs, making it possible for those don't have cable/satellite television to see this program as well as making it possible for children to watch this cartoon character again and again at their convenience, or the convenience of the parents. This very popular television program, in which maps are employed in every episode in a systematic fashion, must have some impacts on the knowledge of preschool children related to maps and on their readiness to learn more about maps and geography (Carter, 2008). In DtE, they get introduced to some different environments such as rivers, forests, islands, snow, mountains with snow on them. These are fantasy environments, but the images expand the world for very young children (Carter, 2012). The use of maps certainly contributes to spatial awareness and the sense of direction. DtE also contributes to at least three things that Catling (2006) looks for:

1. Young children's language development and skill, such as whether they have the vocabulary to name/describe features;

2. Young children's spatial awareness, their sense of direction and their ability to 'map' their familiar territory 'in their heads';

3. The physical skills that young children may have begun to develop, including coordination (as cited in Carter, 2008). 
In this study, researcher examined the effect of a cartoon which appeals to a large portion of children on spatial ability which has a quite important role in both their childhood and adulthood in many areas like mathematics, science and, engineering (Schutte et al., 2011; Casey et al., 2008; Levine, Ratliff, Huttenlocher, \& Cannon, 2011; Ehrlich, Levine, \& Goldin-Meadow, 2006; Tzuriel \& Egozi, 2010). For this purpose, 77 different episodes of Dora the Explorer were watched by a group of preschool children, whereas the other group has continued to their curriculum in a different preschool.

\section{Method}

\section{Research design}

In this study, the effects of DtE cartoon on the preschool children's spatial concept acquisitions and spatial abilities are determined. Post-test only with control group model, which is an experimental design, is used in the research in order to identify the existing phenomena in a controlled manner. There are two groups created with objective placement in a post-test only control group model. One of the groups is used as the control group and the other one is as the experimental group. Participants have been randomly allocated to their groups; post-test differences on the outcome measure should be the same as the difference in change scores of experimental and control groups in the classic experimental group. In many studies, it is either impossible or unnecessary to apply pre-tests to the groups. It can be assumed that creating groups with objective placement can be enough to ensure similarities before the experiment. In this way, negative effects of preexperimental measurement on internal and external validity may be avoided (Büyüköztürk, 2001; Vaus, 2001). In order to provide similar conditions before the experiment, researcher has made sure that children included in the sampling group did not go to a preschool and did not see DtE before. Furthermore, children watched the cartoon in the first semester when the school has started. Therefore, childrens' spatial concept acquisition and spatial abilities were assumed to be equal and the comparison of only post-tests was included in the study. The dependent variables in the design are the preschool children's "Spatial Concept Acquisitions" and, "Spatial Abilities", whereas the independent variable is only the effect of "DtE Cartoon". In the research, the children in the experimental group have watched DtE cartoons in addition to their curriculum in their settings, while the control group continued to follow the curriculum given by their teacher.

\section{Participants}

As the study group, 80, 60-71 month old children with normal development, 40 of whom were in experimental group (20 females, 20 males) and the other 40 of whom were in the control group (23 females and 17 males) 
were selected in total from two different public preschools of Provincial Directorate for National Education, in a city which is a province of Turkey located in central Anatolia. The similarities of socioeconomic levels, accessibility and time factors were taken into consideration while determining the schools for the study group. The zoning map of the city, prepared by the State Institute of Statistics based on economic levels, was used to determine the proximity of the social-economic statuses, also preschools were located in the same district. The teachers' opinions, class structure and students' characteristics were considered during the selection of the classes in the schools. Experimental and control groups were determined via random assignment method. Besides, classes were selected without changing their structures.

\section{Materials}

\section{The Bracken Basic Concept Scale, Third Edition: Receptive (BBCS- III:R)}

The Bracken Basic Concept Scale, Third Edition: Receptive (BBCSIII:R) form, which was developed by Bruce A. Bracken in 1984, is used in the study as a data collection tool. BBCS-III:R form, revised for the third time in 2006, was developed in order to assess basic concept development of children in the age range of three years zero month through six years eleven months. Depending on the child's age and ability, it takes 30-40 minutes for a child to complete the scale which consists of 10 subscales and 282 items.

In this research, direction/position subscale of BBCS-III:R is used in order to assess the spatial concept acquisitions of the children. Direction/position subscale includes relational terms that describe the placement of one object relative to another, the position of an object relative to itself or an unspoken second object, or a direction of the placement (Bracken, 2006). This subscale consists of 62 items.

As part of the content validity study of the scale, experts of early child development and education have assessed the appropriateness of the instructions and scale items in terms of statement, the appropriateness of items in relation to 60-71 month old children's direction/position concept development, the appropriateness of scale items for Turkish culture and appropriateness of the pictures in the scale for 60-71 month old children. The scale was revised and finalized in accordance with the opinions of the experts. In the reliability study, the reliability value of Kuder Richardson (KR20) was calculated. According to the analysis, it was found out that the reliability coefficient of direction/position subscale of BBCS-III:R form was (KR20) 0.96 . The high level of the reliability coefficient value shows that the scale is reliable (Angın, Arı, Deniz, \& Hamarta, 2016). 


\section{Spatial ability games}

Two spatial ability games were prepared by the researcher to identify children's spatial abilities. Two different map patterned carpets were used, which were patterned and colored by houses, roads, bridges, crossroads, farms and pedestrian crossings, for the games. In the first game, the children were expected to move forward on carpet in accordance with the instructions given by the researcher. In the second game, the researcher moved forward on the other carpet and the children were expected to describe the movements. Toy cars were used in the games in order to move in line. There were five movements and spatial concepts in each game. Each correct instruction or statement that the children move or describe is counted as one point and maximum five points can be got from each game. Instructions and movements used in the games are presented below.

\section{Spatial ability-The first game}

The instructions given to the children by the researcher are as follows:

1- Move forward by crossing the pedestrian crossing and the bridge.

2- Continue to the left and drive until you reach the house with redyellow roof.

3- Turn right at the house and move towards the crossroad.

4- Continue driving until passing the sheep.

5- Go and past the two pedestrian crossings ahead and then turn left. Park your car in the parking lot by following the directions.

\section{Spatial ability-The second game}

Movements were performed on the map patterned carpet by the researcher, and the children were encouraged to describe the movements are as below:

1- You proceeded forward and went too far.

2- You passed through the house opposite the bridge.

3- You continued going through the sheep and cows (by the sheep).

4- You moved towards the creek and crossed over the bridge.

5- You turned right and parked your car.

\section{Procedure}

The children in the experimental group watched 77 episodes of DtE in total (season

(http://en.wikipedia.org/wiki/List_of_Dora_the_Explorer_episodes\#Season_ 3_.282003.E2.80.932005.29) three days in a week. The children in the control group didn't watch DtE and the researcher didn't interfere with the teachers' traditional instruction. Accordingly, the hypothesis which claimed that the post-test scores of children who watched DtE from spatial concept acquisition 
and spatial ability games (first-second) were significantly higher than the posttest scores of the children who did not watch DtE from spatial concept acquisition and spatial ability games (first-second) was tested in this study. Just after the children watched DtE, The Bracken Basic Concept Scale, Third Edition: Receptive (BBCS-III:R) Form direction/position subscale and Spatial Ability games were implemented to the experimental and control groups. The average of children's post-test scores measured by "BBCS-III:R Form Direction/Position Subscale" and "Spatial Ability Games (first-second)" in both groups were compared via independent sample t-test.

\section{Findings and Discussion}

Findings related to the effects of DtE cartoon on preschool children's spatial concept acquisitions and spatial abilities are presented below in three hypotheses.

The first hypothesis related to the study is: "There is a statistically significant difference between the average post-test scores of the children, obtained by BBCS-III:R form direction/position subscale, in the experimental group watching DtE and children in the control group attending traditional instruction." In order to test this hypothesis, the average of post-test scores of the children in the experimental and control groups were compared via independent sample t-test; and the results of this comparison are presented in Table 1.

Table 1. Independent sample t-test results regarding BBCS-III:R form direction/position subscale post test score averages of children in experimental and control groups

\begin{tabular}{ccccccc}
\hline & Groups & $\mathbf{n}$ & $\overline{\mathbf{x}}$ & Sd & $\mathbf{t}$ & $\mathbf{p}$ \\
\hline $\begin{array}{c}\text { BBCS-III:R } \\
\begin{array}{c}\text { Form } \\
\text { Direction/Position } \\
\text { Subscale }\end{array}\end{array}$ & Experimental & 40 & 54.42 & 4.55 & & \\
\hline & Control & 40 & 37.82 & 11.88 & & $0.000^{*}$ \\
& & & & & \\
& & & & & &
\end{tabular}

As it is apparent in Table 1, the average post-test scores, obtained by BBCS-III:R form direction/position subscale, of the experimental group's children are significantly higher than control group's average scores ( $\mathrm{p}<0.001)$. Considering BBCS-III:R form direction/position subscale post-test score averages regarding the groups, average post-test scores of the children in the control group is found as $\bar{x}=37.82$; whereas, average post-test scores of the children in the experimental group is found to as $\bar{x}=54.42$. On the basis of the data presented in Table 1, it can be argued that spatial concept acquisitions of the children in the experimental group watching DtE is higher than spatial concept acquisitions of the children in the control group. On the grounds of these results, it can be put forth that DtE affects the children's 
spatial concept acquisitions positively and makes children more successful. The reasons for this can be the facts that DtE show is highly interactive and Dora's young viewers are encouraged throughout the show to respond to Dora and to actively participate in the adventure through physical movement (Nickelodeon, 2013b). Besides, DtE uses and performs spatial concepts both orally and physically with instructions in order to reach the target in each episode, which may be effective in children's acquisitions of spatial concepts.

A review of literature reveals that maps comprise spatial information about the surroundings and they affect our spatial perceptions by helping us to think of an area more abstractly and in relation to the other areas. Therefore, maps are considered to be tools that can be used in the improvement of spatial perceptions (Anderson \& Leinhardt, 2002; Liben \& Downs, 1993; Staub \& Stern, 1997; Liben, 2001-2002). Numerous researcher propose that children's spatial abilities affect their spatial perceptions (Uttal, 2000; Carter, 2008; Liben, 2000-2001; Liben \& Downs, 2001). The researcher emphasize that the right and appropriate television programs can be pedagogic for children and they may have positive effects on them (Anderson \& Pempek 2005; Linebarger \& Walker 2005). In addition, Linebarger and Walker (2005) have identified in their research that vocabulary knowledge of 30 months old children watching television programs such as Dora the Explorer and Blue's Clues is much more than the vocabulary knowledge of the ones who don't. Theoretical knowledge is in parallel with the finding of this study.

The second hypothesis related to the study is: "There is a statistically significant difference between spatial ability and the average post-test scores of the first game played by the children in the experimental group watching DtE and the children in the control group attending traditional instruction". In order to test this hypothesis, the average of post-test scores of the children in the experimental and control groups were compared to each other via independent sample t-test. The results regarding the data are presented in Table 2.

Table 2. Independent sample t-test results regarding the comparison between spatial ability the first game post test score averages of the children in experimental and control groups

\begin{tabular}{|c|c|c|c|c|c|c|}
\hline & Groups & $\mathbf{n}$ & $\overline{\mathbf{x}}$ & Sd & $\mathbf{t}$ & $\mathbf{p}$ \\
\hline \multirow{2}{*}{$\begin{array}{l}\text { Spatial Ability } \\
\text { the First Game }\end{array}$} & Experimental & 40 & 4.65 & 0.53 & \multirow{2}{*}{12.56} & \multirow{2}{*}{$0.000 *$} \\
\hline & Control & 40 & 3.02 & 0.61 & & \\
\hline
\end{tabular}

According to the data given by Table 2, it was seen that the average scores of post-test of the children in the experimental group regarding spatial ability - the first game is significantly higher than average post-test scores of 
the children in the control group $(\mathrm{p}<0.001)$. Considering the average post-test scores of the groups, in the control group children is found to be $\bar{x}=3.02$ and the average post-test score of the children in the experimental group is found to be $\bar{x}=4.65$. These results show that DtE makes a positive contribution to the spatial ability development of the children in the experimental group and makes them more successful compared to the children in the control group.

The children's capability in spatial abilities is closely related to their ages and the educational opportunities provided to them (Lysaker, 2006). It is also highly related to the children's exposure to natural, qualified and different experiences besides planned trainings (Catling, 2005; Wiegand, 1999; Goria \& Papadopoulou, 2008). Marzolf and DeLoache (1994) put forth that if four year old children are taught how to use maps, they will perform the instructions on a map provided to them relating to their real surroundings; in this context, Kynigos, Yiannoutsou, Dimitrakopoulou and Ioannidou (2001) have suggested that the reliable and meaningful learning environments offered to children affect their map understanding and spatial concept acquisitions. Blades, Sowden and Spencer (1995) have suggested that one way to stimulate young children's map abilities is to encourage their awareness of spatial relationships by explicit teaching and training. These findings in the literature support the findings of the second hypothesis of the study.

The third hypothesis of the study is as follows: "There is a statistically significant difference between spatial ability and the average scores of posttest of the second game taken by the children in the experimental group watching DtE and the children in the control group attending traditional instruction". The results of t-test for independent sample regarding the comparison between the average post-test scores of the children in the experimental and control groups are presented in Table 3.

Table 3. Independent sample t-test results regarding the comparison between the spatial ability - the second game post test score averages of the children in the experimental and control groups

\begin{tabular}{|c|c|c|c|c|c|c|}
\hline & Groups & $\mathrm{n}$ & $\bar{x}$ & $\mathrm{Sd}$ & $\mathrm{t}$ & $\mathrm{p}$ \\
\hline \multirow{2}{*}{$\begin{array}{l}\text { Spatial Ability } \\
\text { the Second Game }\end{array}$} & Experimental & 40 & 4.35 & 0.62 & \multirow[t]{2}{*}{8.38} & \multirow[t]{2}{*}{$0.000 *$} \\
\hline & Control & 40 & 3.22 & 0.57 & & \\
\hline
\end{tabular}

When Table 3 was examined, it was found that the average post-test scores of spatial ability - second game in the experimental group is significantly higher than the average scores of the children in the control group $(\mathrm{p}<0.001)$. Considering the average post-test scores of spatial ability - second game of the groups, the average post-test scores of the children in the control 
group is found as $\bar{x}=3.22$; whereas, average post-test scores of the children in the experimental group is found to be $\bar{x}=4.35$. This finding shows that DtE makes a positive contribution to the spatial ability development of the children in the experimental group and makes them more successful compared to the children in the control group.

Dora gives youngsters many concepts, skills and capabilities that are foundation of learning geography and for using maps and graphic imagery (Carter, 2008). According to a study conducted by Pruden, Levine and Huttenlocher (2011), it was suggested that children's spatial language production is a significant predictor of their later spatial skills and talking about the spatial world is relatively easy way to enhance young children's spatial language as well as their spatial thinking. Other experimental studies related to this issue have shown that the children who heard spatial language are more successful in spatial tasks than other children who did not hear spatial language (Hermer-Vasquez, Moffet, \& Munkholm, 2001; Dessalegn \& Landau, 2008; Szechter \& Liben, 2004). In addition, Baenninger and Newcombe reported that spatial ability can indeed be improved with training (as cited in Tzuriel and Egozi, 2010).

\section{Conclusion}

The analysis of the data obtained through the post-test scores showed that the DtE cartoon provides a significant difference between the spatial concept acquisition and spatial ability of preschool children in the experimental and control groups. According to both BBCS-III:R form direction/position subscale and spatial ability games scores, the experimental group improved significantly more than the control group.

Considering the time spent by the children watching cartoons, it emerges as a very significant and noteworthy issue to offer the children programs comprising pedagogic and instructional content in order to make this period of time more qualified. If the right television program with educational content is selected, then the cartoon may serve to improve developmental skills of the children. Therefore, the main reason for including DtE cartoon in this study is that it has a pedagogic content and supports children's development of spatial concept acquisitions and spatial abilities.

The findings obtained from the study show consistency with other research findings and theoretical knowledge found in the literature review; and it is identified that preschool children are able to improve their spatial abilities and spatial concept acquisitions when appropriate educational conditions are provided for them. Conversations and experiences containing spatial words and images refer to spatial features of the objects that are effective in supporting the development of map using abilities. 


\section{Limitations and recommendations}

Although this study reveals meaningful difference between groups with post-test only research design, future researches may be conducted with classic pre-test/post-test experimental design to eliminate the post-test only design inefficacy. On the other hand the studies about spatial ability and map using are investigated, it is seen that gender factor was mentioned frequently and results suggesting that males have better spatial ability and map using skills than females. As a recommendation for the future studies, the factor of the gender may be taken into account during the research.

\section{References:}

1. Anderson, K. C., \& Leinhardt, G. (2002). Maps as representations: Expert novice comparison of projection understanding. Cognition and Instruction, 20, 283-321. doi: 10.1207/S1532690XCI2003_1

2. Anderson, D. R., \& Pemkek, T. A. (2005). Television and very young children. American Behavioral Scientist, 48, 505-522. doi: 10.1177/0002764204271506

3. Angin, D. E., Ar1, R., Deniz, M. E., \& Hamarta, E. (2016). The Validity and Reliability Study of the Bracken Basic Concept Scale, Third Edition: Receptive (BBCS-3:R) Form for 60-71 Month Children. Unpublished manuscript.

4. Blades, M. \& Spencer, C. (1986). Map use by young children. Geography, 71, 47-52. Retrieved from http://www.jstor.org/stable/40571042

5. Blades, M., Sowden, S., \& Spencer, C. (1995). Young children's use of spatial relationships in tasks with maps and models. Cartographica: The International Journal of Geographic Information and Geovisualization, 32, Monograph 46, 18-29. doi: 10.3138/381M3735-2833-8151

6. Bracken, B. A. (2006). Bracken Basic Concept Scale-Third Edition: Receptive. Examiner's Manual. San Antonio, USA: Pearson.

7. Bremner, G. J., \& Andreasen, G. (1998). Young children's ability to use maps and models to find ways in novel spaces. British Journal of Developmental Psychology, 16, 197-218. doi: 10.1111/j.2044835X.1998.tb00919.x

8. Büyüköztürk, Ş. (2001). Deneysel Desenler. Ankara: Pegema Yayıncilik.

9. Carter, J. R. (2008). Dora the Explorer: Preschool geographic educator. Journal of Geography, 107, (3): 77-86. doi: 10.1080/00221340802419377 
10. Carter, J. R. (2012). Exploring with Dora. Glacial Deposits, 40, 26-29. Retrieved from http://geo.illinoisstate.edu/downloads/glacial_deposits40.pdf

11. Casey, B. M., Andrews, N., Schindler, H., Kersh, J.E., Samper, A., \& Copley, J. (2008). The development of spatial skills through interventions involving block building activities, cognition and instruction. Cognition and Instruction, 26, 269-309. doi: $10.1080 / 07370000$

12. Catling, S. (2005). Developing children's map understanding. Retrieved from http://www.geography.org.uk/gtip/thinkpieces/makingmaps/\#787

13. Dalacosta, K., Kamariotaki-Paparrigopoulou, M., Palyvos, J. A., \& Spyrellis, N. (2009). Multimedia application with animated cartoons for teaching science in elementary education. Computers and Education, 52, 741-748. doi: 10.1016/j.compedu.2008.11.018

14. Dessalegn, B., \& Landau, B. (2008). More Than Meets the Eye: The Role of Language in Binding and Maintaining Feature Conjunctions. Psychological Science, 19, 189-195. doi: 10.1111/j.14679280.2008.02066

15. Dyanne, T. M. (1988). Toy-playing behavior, sex-role orientation, spatial ability, and science achievement of fifth grade students: Are they related? (ED 291 581). Retrieved from http://files.eric.ed.gov/fulltext/ED291581.pdf

16. Ehrlich, S. B., Levine, S. C., \& Goldin-Meadow, S. (2006). The importance of gesture in children's spatial reasoning. Developmental Psychology, 42, 1259 -1268. doi: 10.1037/0012-1649.42.6.1259

17. Goria, S., \& Papadopoulou, M. (2008). Preschoolers using maps: An educational approach. The International Journal of Learning, 15, 173186.

Retrieved

from

http://www.academia.edu/1812227/Preschoolers_using_maps_an_ed ucational_approach

18. Hermer-Vazquez, L., Moffet, A., \& Munkholm, P. (2001). Language, space, and the development of cognitive exibility in humans: the case of two spatial memory tasks. Cognition, 79, 263-299. doi: 10.1016/S0010-0277(00)00120-7

19. Koutsopoulos, K.. C. \& Pigaki, M. (2007). Teaching and learning geography with maps: a conceptual framework. Paper presented at the meeting of International Geographical Union Commission for Geographical Education British Sub-Committee with HERODOT, London.

20. Kynigos, C., Yiannoutsou, N., Dimitracopoulou, A., \& Ioannidou, I. (2001). Children in Choros and Chronos (Report No. C3 Project 
Deliverable D.1.4 - Final Evaluation Report.). Retrieved from http://www.cti.gr/en/RD3/C3/index.php?option=com_content\&view= article\&id $=1310$

21. Levine, S. C., Huttenlocher, J., Taylor, A., \& Langrock, A. (1999). Early sex differences in Spatial Skill. Developmental Psychology, 35, 940-949.

Retrieved

from

http://psychology.uchicago.edu/people/faculty/levine/Levine_et_al_1 999.pdf

22. Levine, S. C., Ratliff, K. R., Huttenlocher, J., \& Cannon, J. (2011). Early puzzle play: A predictor of preschoolers' spatial transformation skill. Developmental Psychology, 48, 530-42. doi: 10.1037/a0025913

23. Liben, L. S., \& Downs, R. M. (1993). Understanding person-spacemap relations: Cartographic and developmental perspectives.

Developmental Psychology, 29, 739-752. doi: 10.1037/00121649.29.4.739.

24. Liben, L. S. (2000). Map use and the development of spatial cognition: Seeing the bigger picture. Developmental Science, 3, 270-274.

25. Liben, L. S., \& Downs, R. M. (2001). This is a chapter. In S. L. G. (Ed.), Psychological perspectives on early childhood education: Geography for young children: Maps as tools for learning environments. (pp. 220-252). Mahwah, NJ: Lawrence Erlbaum Associates.

26. Liben, L. S. (2001). This is a chapter. In M. G. (Ed.), Spatial schemas and abstract thought: Thinking through maps. (pp. 44-77). Cambridge, MA: MIT Press.

27. Liben, L. S. (2002). This is a chapter. In U. G. Editor (Ed.), Blackwell handbook of childhood cognitive development: Spatial development in children: Where are we now? (pp. 326-348). Oxford, UK: Blackwell Publishers.

28. Linebarger, D. L., \& Walker, D. (2005). Infants' and Toddlers' Television Viewing and Language Outcomes. American Behavioral Scientist, 48, 624-645. doi: 10.1177/0002764204271505

29. List of Dora the Explorer Episodes http://en.wikipedia.org/wiki/List_of_Dora_the_Explorer_episodes\#S eason_3_.282003.E2.80.932005.29

30. Lysaker, J. T. (2006). Young children's readings of wordless picture books: What's "self" got to do with it". Journal of Early Childhood Literacy, 6, 33-55. doi: 10.1177/1468798406062174

31. Marzolf, D. P., \& DeLoache, J. S. (1994). Transfer in young children's understanding of spatial relations. Child Development, 65, 1-15. Retrieved from http://www.jstor.org/stable/1131361 
32. Mohler, J. L. (2008). Examining the spatial ability phenomenon from the student's perspective. Engineering Design Graphics Journal, 72, $1-15$. Retrieved from http://www.edgj.org/index.php/EDGJ/article/view/50/49

33. National Research Council of the National Academy. (2006). Learning to think spatially. Washington, D.C.: The National Academies Press.

34. Newcombe, N. S. (2010). Increasing math and science learning by improving spatial thinking. American Educator. Retrieved from http://www.aft.org/pdfs/americaneducator/summer2010/Newcombe.p df

35. Newcombe, N. S., \& Shipley, T. F. (2012). Thinking about spatial thinking: New typology, new assessments. Retrieved from http://spatiallearning.org/publications_pdfs/Aix\%20Paper\%20on\%20 Spatial\%20Skills\%20FINAL\%20FOR\%20PUBLICATION_final.pdf

36. Nickelodeon, J. (2013a). About Dora the Explorer. Retrieved from http://www.nickjr.com/dora-the-explorer/about-dora-theexplorer/about-dora-the-explorer-tv-show.html

37. Nickelodeon, J. (2013b). Dora the Explorer Curriculum. Retrieved from http://www.nickjr.com/dora-the-explorer/about-dora-theexplorer/dora-the-explorer-curriculum.html

38. Peter, M., Glück, J., \& Beiglböck, W. (2010). Map understanding as a developmental marker in childhood. Journal of Individual Differences, 31, 64-67. doi: 10.1027/1614-0001/a000011

39. Poole, C., Miller, S. A., \& Church, B. E. (2006). Development: Ages \& Stages--spatial awareness. Early Childhood Today, 20, 25-30. Retrieved from http://eric.ed.gov/?id=EJ738512

40. Pruden, S.M., Levine, S. C., \& Huttenlocher, J. (2011). Children's spatial thinking: Does talk about the spatial world matter? Developmental Science, 14, 1417-1430. doi: 10.1111/j.14677687.2011.01088.x

41. Schutte, A. R., Fleharty, H., Hund, A.M., Uttal, D. H., Sauter, M., Simms, N., \& Gentner, D. (2011, July). The Development of Spatial Cognition During Childhood: Extending Understanding of Perception, Memory, Language, Maps, and Gestures. Paper presented at the meeting of 33rd Annual Meeting of the Cognitive Science Society, Boston, Massachusetts.

42. Staub, F. C., \& Stern, E. (1997). Abstract reasoning with mathematical constructs. International Journal of Education Research, 27, 63-75. doi: 10.1016/S0883-0355(97)88444-3

43. Szechter, L.E., \& Liben, L. S. (2004). Parental Guidance in Preschoolers' Understanding of Spatial-Graphic Representations. 
Child Development, $\quad 75, \quad 869-885 . \quad$ doi: $10.1111 /$ j.14678624.2004.00711.x

44. Tzuriel, D., \& Egozi, G. (2010). Gender differences in spatial ability of young children: The effects of training and processing strategies. Child Development, 81, 1417-1430. doi: 10.1111/j.14678624.2010.01482.x

45. Uttal, D. H., \& Wellman, H. M. (1989). Young children's representation of spatial information acquired from maps. Developmental Psychology, 25, 128-138. Retrieved from http://www.researchgate.net/publication/232500930_Young_children 's_representation_of_spatial_information_acquired_from_maps/file/6 0b7d52ba550f5cd22.pdf

46. Uttal, D. H. (2000). Seeing the big picture: Map use and development of spatial cognition. Developmental Science, 3, 247-264. doi: 10.1111/1467-7687.00119

47. Vaus, D. (2001). Research design in social research. London: SAGE Publication.

48. Wiegand, P. (1999). Children's understanding of maps. International Research in Geographical and Environmental Education, 8, 66-68. doi: 10.1080/10382049908667591 